\title{
Validation of a Paper Chromatographic Methodology as an Alternative for Determination of the Radiochemical Purity of $\mathrm{Na}^{18} \mathrm{~F}$
}

\author{
Natalia M. Leonardi ${ }^{1}$, Guillermo A. Casale ${ }^{2}$ Jorge Nicolini $^{2}$, Patricia D. Zubata ${ }^{2}$, María J Salgueiro ${ }^{1}$, \\ and Marcela B. Zubillaga ${ }^{1}$ \\ ${ }^{1}$ Laboratorio de Radioisótopos, Facultad de Farmacia y Bioquímica, Universidad de Buenos Aires, Buenos Aires, Argentina; and \\ ${ }^{2}$ Laboratorios BACON S.A.I.C., Buenos Aires, Argentina
}

The aim of the present work was to validate a paper chromatography system as an alternative way to determine the radiochemical purity of $\mathrm{Na}^{18} \mathrm{~F}$. Methods: The evaluated parameters were specificity, limit of quantification, measurement interval, linearity, precision, accuracy, and robustness. Results: The proposed method proved to be linear $\left(P>0.05 ; r^{2}=1.000\right)$, precise (relative SD, 8.6\%), accurate (mean recovery, $95.9 \%$; relative $\mathrm{SD}, 1.5 \%-1.8 \%$ ), and robust under different conditions since no influence of the operative variables on the chromatographic performance was observed. Conclusion: This system can be used as a reliable alternative method to determine the radiochemical purity of $\mathrm{Na}^{18} \mathrm{~F}$ samples that can be easily performed in PET radiopharmacies at low cost.

Key Words: validation; $\mathrm{Na}^{18} \mathrm{~F}$; radiochemical purity

J Nucl Med Technol 2012; 40:271-274

DOI: 10.2967/jnmt.112.107664

$\mathbf{T}$ he use of $\mathrm{Na}^{18} \mathrm{~F}$ for bone scintigraphy dates back to the early 1960s (1). However, the unavailability of clinical cyclotrons and the development of ${ }^{99 \mathrm{~m}}$ Tc-labeled agents for bone scintigraphy brought about the prompt replacement of $\mathrm{Na}^{18} \mathrm{~F}$ with ${ }^{99 \mathrm{~m}} \mathrm{Tc}$ agents for clinical use (2). Some decades later, $\mathrm{Na}^{18} \mathrm{~F}$ was rediscovered when, in 2000 , the Food and Drug Administration approved it as a radiopharmaceutical for bone scintigraphy as part of its modernization in the handling of new drug applications (3). Since then, many reports have proposed the use of this agent as a sensitive and specific radiopharmaceutical for detection of benign and malignant osseous abnormalities that also allows the regional characterization of lesions in metabolic bone diseases $(4,5)$.

\footnotetext{
Received Apr. 18, 2012; revision accepted Jun. 26, 2012.

For correspondence or reprints contact: Natalia M. Leonardi, Laboratorio de Radioisótopos, Facultad de Farmacia y Bioquímica, Universidad de Buenos Aires, Junín 956 Piso Bajo (1113), Buenos Aires, Argentina.

E-mail: nataliamleonardir@gmail.com.

Published online Sep. 27, 2012.

COPYRIGHT @ 2012 by the Society of Nuclear Medicine and Molecular Imaging, Inc.
}

$\mathrm{Na}^{18} \mathrm{~F}$ is a cyclotron-produced radiopharmaceutical, and the only reported and validated methodology for determining its radiochemical purity (RP) is high-performance liquid chromatography, which requires special equipment (6-8). Nevertheless, previous studies demonstrated the efficacy of a paper chromatography method for the RP determination of $\mathrm{Na}^{18} \mathrm{~F}$ (9). This work was performed to investigate the possibility of applying the paper chromatography method as an alternative to high-performance liquid chromatography for ${ }^{18} \mathrm{~F}$-fluoride RP analysis.

\section{MATERIALS AND METHODS}

\section{$\mathrm{Na}^{18} \mathrm{~F}$ Production}

${ }^{18} \mathrm{~F}$-fluoride was produced on an $18-\mathrm{MeV}$ cyclotron, Cyclone $18 / 9$ (IBA), by the ${ }^{18} \mathrm{O}(\mathrm{p}, \mathrm{n}){ }^{18} \mathrm{~F}$ nuclear reaction. The niobium target (with yield of $8.7 \mathrm{GBq} / \mu \mathrm{A}$ at saturation) was filled with $2 \mathrm{~mL}$ of enriched ${ }^{18} \mathrm{O}$ water, which was irradiated with protons for $10 \mathrm{~min}$ at anintensity of $40 \mu \mathrm{A}$. The solution containing ${ }^{18} \mathrm{~F}^{-}$ was transferred into an automatic synthesis module, Synthera (IBA), prepared with a commercial reagent kit and accessories for $\mathrm{Na}^{18} \mathrm{~F}$ production. ${ }^{18} \mathrm{~F}$-fluoride ions were trapped in an anion exchange column (Sep-Pak Light Accell Plus QMA; Waters Corp.) and were theneluted with a $0.9 \% \mathrm{NaCl}$ solution. Finally, the resulting $15 \mathrm{~mL}$ of $\mathrm{Na}^{18} \mathrm{~F}$ were dispensed into a sterile, pyrogen-free vial through a $0.22-\mu \mathrm{m}$ filter (Millipore) in a dispensing unit (Dispensing Hot Cell; Becquerel and Sievert Co., Ltd.).

\section{Physicochemical Quality Control}

Radionuclidic purity was evaluated by $\gamma$-ray spectrometry (PX4 TeCd detector; Amptek).

Radionuclidic identity was determined by estimation of the halflife of ${ }^{18} \mathrm{~F}$, which was calculated after measuring the radioactivity decay of the sample over a 20-min period in a radioisotope dose calibrator (Vexcal AV-02; Veccsa S.A.). The equation used is shown below:

$$
\mathrm{T}_{1 / 2}=\ln 2\left(\mathrm{t}-\mathrm{t}_{0}\right) / \ln \left(\mathrm{a} / \mathrm{a}_{0}\right),
$$

where $T_{1 / 2}$ is half-life, $t-t_{0}$ is the time interval (in minutes), a is activity measured after $20 \mathrm{~min}$, and $\mathrm{a}_{0}$ is initial activity.

The $\mathrm{pH}$ of $\mathrm{Na}^{18} \mathrm{~F}$ was measured using indicator strips of different ranges (universal indicator, $\mathrm{pH} 1-14$, and special indicators, $\mathrm{pH}$ 2.5-4.5, 4.0-7.0, and 6.5-10.0; Merck) depending on the $\mathrm{pH}$ 
range of the samples. The results were compared with standard $\mathrm{pH}$ buffer, and the estimated value was registered.

\section{Validation of Chromatographic Studies}

The paper chromatographic system under evaluation was previously reported by Noto and Nicolini (9). Briefly, $5 \mu \mathrm{L}$ of $\mathrm{Na}^{18} \mathrm{~F}$ samples were spotted on a $15-\mathrm{cm}$ strip of Whatman 1 paper as the stationary phase and developed with $0.15 \mathrm{M}$ sodium acetate as the mobile phase for $30 \mathrm{~min}$. Under these conditions, ${ }^{18} \mathrm{~F}^{-}$ion will be located at an $\mathrm{R}_{\mathrm{f}}$ of $0.9-1.0$, and possible impurities will be located at an $\mathrm{R}_{\mathrm{f}}$ of $0.0-0.1$. In this work, the methodology for $\mathrm{Na}^{18} \mathrm{~F} \mathrm{RP}$ determination was evaluated and validated by following international standards such as those of the International Committee of Harmonization (10) and the U.S. Pharmacopoeia (11). The evaluated parameters were specificity, limit of quantification, measurement interval, linearity, precision, accuracy, and robustness.

Linearity was determined using ${ }^{18} \mathrm{~F}$ in samples containing activity concentrations of $11.25 \%$ (sample A), $16.8 \%$ (sample B), 23.8\% (sample C), 31.9\% (sample D), 47.0\% (sample E), and $100 \%$ (sample F). To test linearity, samples from the batch were diluted in $0.9 \% \mathrm{NaCl}$ solution to reach the activity concentrations evaluated. One operator evaluated instrumental precision (as repeatability) by performing 6 replicates of 1 sample (sample E; $47 \%$ of activity concentration). Accuracy was assessed by performing 3 replicates for each of 3 samples having different activity concentrations (samples B, D, and F). Finally, robustness for chromatographic studies was evaluated by the variation of $\mathrm{pH}$ over 5 replicates of 2 samples having different final $\mathrm{pH}$ values: sample 1 (final $\mathrm{pH}, 4.0$, with $1 \mathrm{~N} \mathrm{HCl}$ ) and sample 2 (final $\mathrm{pH}, 8.0$, with $1 \mathrm{~N} \mathrm{NaOH}$ ), compared with control $(\mathrm{pH}, 5.8)$.

Each chromatogram was measured using an MS-1000F system (Eckert and Ziegler Radiopharma, Inc.), which consists of a MiniScan thin-layer radiochromatograph with a single-photomultipliertube Flow-Count integrator. The results for linearity, accuracy, and precision were obtained as total area under the main peak (counts). Linearity results included the equation obtained for the linear regression and its correlation coefficient $\left(r^{2}\right)$, with a $P$ value of less than 0.05 considered statistically significant (12). Accuracy results are shown as the percentage of peak radioactivity recovered at an $\mathrm{R}_{\mathrm{f}}$ of $0.9-1.0$ for the different samples, including the percentage relative SD (RSD) for replicates. Instrumental precision results are shown as RSD, including the percentage coefficient of variation. Finally, robustness results are shown as variations in the $R_{f}$ for replicates of samples 1,2 , and controls, with the results compared by ANOVA (13).

\section{RESULTS}

A total batch of $66.6 \mathrm{GBq}$ of $\mathrm{Na}^{18} \mathrm{~F}$ was produced in yield higher than $98 \%$. The final activity concentration of the batch was $4.44 \mathrm{GBq} / \mathrm{mL}$.

\section{Physicochemical Quality Control}

The $\gamma$-ray spectrum for radionuclidic purity assay showed only 1 main peak at $0.511 \mathrm{MeV}$. The radionuclidic identity of the final product, performed by the half-life estimation, was $110.2 \pm 0.5 \mathrm{~min}$, and its $\mathrm{pH}$ was 5.8 .

\section{Validation of Chromatographic Studies}

The specificity of this chromatographic system has been previously demonstrated in a study that determined the $R_{f}$ of pure fluoride and the ability of the system to separate the possible production impurities (9).

With regard to the other parameters, the regression curve proved linearity $\left(r^{2}=1.000 ; P>0.05\right)$, with a $y$-intercept of 20,770 $\pm 13,060$, a slope of $1,146,000 \pm 268.5$, and an absolute sum of squares of 1,537e +009 (Fig. 1). The accuracy studies demonstrated nearly $100 \%$ recovery $(92.8 \%-98.2 \%$; mean, $95.9 \%$ ), with RSD values of $1.5 \%-1.8 \%$ for samples of the 3 activity concentrations (Table 1). In the repeatability studies (instrumental precision), the RSD was 8.6\% (Table 2) and there were no significant differences in the recoveries obtained from replicates of sample E. The results of the robustness study showed that the operative variables had no influence on chromatographic performance, since differences in the $\mathrm{pH}$ of the $\mathrm{Na}^{18} \mathrm{~F}$ product did not significantly affect the $\mathrm{R}_{\mathrm{f}}$ of ${ }^{18} \mathrm{~F}^{-}$in the samples $\left(\mathrm{R}_{\mathrm{f}}\right.$ of $0.9-1.0$ for all replicates of samples-both $\mathrm{pH} 4$ and $\mathrm{pH}$ 8), with an RSD of $4.5 \%$ (data not shown).

\section{DISCUSSION}

Radionuclidic purity as evaluated by $\gamma$-ray spectrometry, and radionuclidic identity as determined by the half-life estimation and $\mathrm{pH}$ for $\mathrm{Na}^{18} \mathrm{~F}$, were in accordance with those found in the U.S. Pharmacopeia (7).

The limit of detection is the concentration derived from the smallest response that can be detected with reasonable

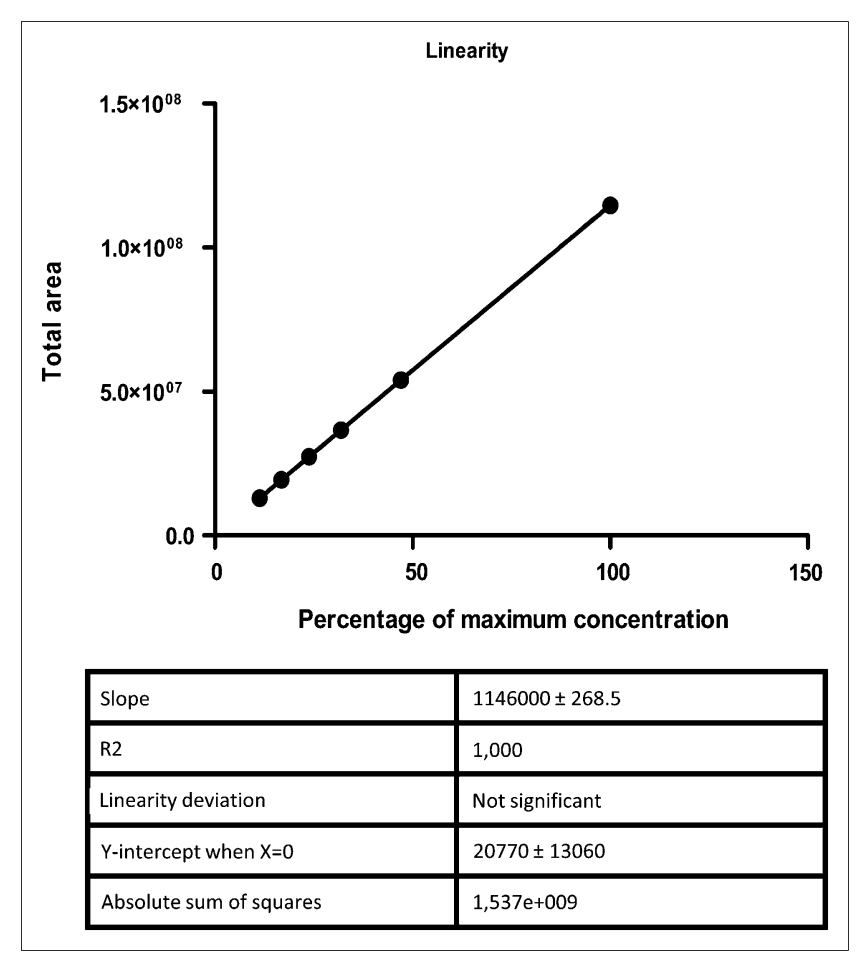

FIGURE 1. Linearity of chromatographic validation study. 
TABLE 1

Accuracy of Chromatographic Validation Study

\begin{tabular}{lcccc}
\hline & \multicolumn{5}{c}{$\begin{array}{c}\text { Mean } \\
\text { Added } \\
\text { activity } \\
\text { Sample }\end{array}$} & $\begin{array}{c}\text { recovered } \\
\text { activity } \\
\text { (counts) }\end{array}$ & $\begin{array}{c}\text { Mean } \\
\text { (counts) }\end{array}$ & $\begin{array}{c}\text { recovery (\%) } \\
\text { RSD (\%) }\end{array}$ \\
\hline B & $19,256,688$ & $17,869,696$ & 92.8 & 1.5 \\
& & $18,911,648$ & 98.2 & \\
D & $36,600,448$ & $18,679,344$ & 97 & \\
& & $34,036,352$ & 95.7 & 1.8 \\
F & & $35,230,261$ & 96.2 & \\
& $116,917,160$ & $110,810,920$ & 94.8 & 1.8 \\
& & $114,615,600$ & 98 & \\
& & $114,114,560$ & 97.6 & \\
\hline
\end{tabular}

certainty for a given analytic procedure (14). The detection threshold of a counting system is expressed in terms of background counting rates. The minimum detectable activity of a counting system is defined by the National Bureau of Standards as 3 SDs of the background counting rate, where the sample is counted for the same period. Thus, this value is associated with a $99.9 \%$ level of confidence that counts greater than the minimum detectable activity represent valid, detectable radioactivity. Nevertheless, in routine practice, sample volumes for measurements are selected in order to register at least $10,000 \mathrm{cpm}$ (RSD, 1\%) according to the efficiency of radioactivity detection of the equipment. Because radioactivity is a random phenomenon, activity measurements vary statistically and according to a Poisson distribution, and equipment often used for activity measurements can only estimate the real counts in a sample that is determined in a finite period. Therefore, it is not necessary to determine the limit of quantification-unlike highperformance liquid chromatography systems, for which injection volumes for samples are specified because of equipment requirements.

The measurement interval is defined as ranging from the background activity to the maximum measurable activity detected by the equipment under the proposed conditions of use. Background issues were discussed above in

TABLE 2

Precision of Chromatographic Validation Study

\begin{tabular}{lc}
\hline Replicate & Total area (counts) \\
\hline 1 & $62,494,340$ \\
2 & $62,494,341$ \\
3 & $54,824,394$ \\
4 & $54,882,865$ \\
5 & $52,035,468$ \\
6 & $53,503,904$ \\
& \\
\hline RSD $=8.6 \%$ & \\
\hline
\end{tabular}

relation to the randomness of the radioactivity phenomena and the RSD often required in such measurements. Since the measurable maximum activity is defined and limited by factors such as saturation, but can be fitted in the linear range of the detector by changes in measurement efficiency (geometry), it does not need to be determined. Geometric efficiency is defined as the ratio of actually observed counts to the total number of $\gamma$-photons reaching the detector. In these terms, the efficiency of any scintillator detector eventually reaches a point at which it decreases as the activity of the sample measured increases $(15,16)$. Nevertheless, coincidence losses may be avoided by changing the geometry of the sample with regard to the crystal or by placing a lead absorber between the detector and the chromatographic strip $(15,16)$. This versatility in radiation measurements can be accomplished with this kind of equipment and RP methodology but is not possible in high-performance liquid chromatography methodology. Therefore, the interval will vary according to the equipment and measurement conditions selected for the chromatographic strip.

With regard to the other parameters validated, the regression curve proved linearity, accuracy, and precision according to the guidelines of the U.S. Pharmacopoeia and the International Conference of Harmonisation (10-11). The results of the robustness study demonstrated that neither ions such as $\mathrm{Cl}^{-}$and $\mathrm{Na}^{+}$nor $\mathrm{pH}$ affected this parameter. Altogether, these results showed that the reproducibility of the measurements, characterized by the coefficient of variance of the recoveries, agrees with the expected performance parameters of thin-layer chromatography methods for assaying trace compounds (17).

\section{CONCLUSION}

The aim of the present work was to validate a paper chromatography system as an alternative way to determine the RP of $\mathrm{Na}^{18} \mathrm{~F}$. The proposed method proved to be linear, precise, accurate, and robust under different conditions and can easily be performed in PET radiopharmacies at low cost.

\section{ACKNOWLEDGMENTS}

This work was financially supported by project UBACYT 20020100100489 from the University of Buenos Aires. $\mathrm{Na}^{18} \mathrm{~F}$ was kindly donated by Laboratorios Bacon S.A.I.C., Buenos Aires, Argentina.

\section{REFERENCES}

1. Spencer R, Herbert R, Rish WM, Little WA. Bone scanning with $85-\mathrm{Sr}, 87 \mathrm{~m}-\mathrm{Sr}$ and 18-F: physical and radiopharmaceutical considerations and clinical experience in 50 cases. Br J Radiol. 1967;40:641-654.

2. Subramanian G, McAfee JG. A new complex of Tc-99m for skeletal imaging. Radiology. 1971;99:192-196.

3. Positron emission tomography drug products: safety and effectiveness of certain PET drugs for specific indications. Food and Drug Administration Web site. 
Available at: www.fda.gov/ohrms/dockets/98fr/031000a.txt. Accessed September 11, 2012.

4. Bridges RL, Wiley CR, Christian JC, Strohm AP. An introduction to $\mathrm{Na}^{18} \mathrm{~F}$ bone scintigraphy: basic principles, advanced imaging concepts, and case examples. J Nucl Med Technol. 2007;35:64-76.

5. Grant FD, Fahey FH, Packard AB, Davis RT, Alavi A, Treves ST. Skeletal PET with ${ }^{18}$ F-fluoride: applying new technology to an old tracer. J Nucl Med. 2008;49:68-78.

6. The European Pharmacopoeia. 6th ed. Strasbourg, France: the European Directorate for the Quality of Medicine; 2008:1008-1009.

7. 2010 USP-NF. Rockville, MD: United States Pharmacopoeial Convention Inc.; 2009:2409.

8. Li CC, Farn SS, Yeh YH, Lin WJ, Shen LH. Development and validation of an anion-exchange HPLC method for the determination of fluoride content and radiochemical purity in $\left[{ }^{18} \mathrm{~F}\right] \mathrm{NaF}$. Nucl Med Biol. 2011;38:605-612.

9. Noto MG, Nicolini JO. The radiochemical purity determination of ${ }^{18} \mathrm{~F}$ preparations. J Radioanal Chem. 1975;24:85-87.

10. International Conference of Harmonisation (ICH) of Technical Requirements for Registration of Pharmaceuticals for Human Use. Validation of Analytical Procedures. Text and Methodology Q2 (R1). Geneva, Switzerland; November 2005.
11. Validation of compendial methods. In: 2004 USP-NF. Rockville, MD: United States Pharmacopeial Convention Inc.; 2003:2622-2625.

12. Motulosky H, Christopoulos A. Fitting models to biological data using linear and nonlinear regression: a practical guide to curve fitting. San Diego, CA: GraphPad Software Inc.; 2003.

13. Dawson-Sanders B, Trapp R. Capítulo 7: estimación y comparación de medias. In: Bioestadística Médica. Mexico City, Mexico: Manual Moderno; 1997:119147.

14. Hoogerbugge R, Van Zoonen P. Validation of analytical data in research and development environment. In: Fajgelj A, Ambrus A, eds. Principles of Method Validation. Cambridge U.K.: Royal Society of Chemistry. 2000:19-29.

15. Nickel RA. Radiopharmaceutical. In: Early PJ, Sodee DB, eds. Principles and Practice of Nuclear Medicine. 2nd ed. St. Louis, MO: Mosby; 1995:94-117.

16. Early PJ, Miller WH. Chapter 11: Considerations of counting and imaging. In: Early PJ, Sodee DB, eds. Principles and Practice of Nuclear Medicine. 2nd ed. St. Louis, MO: Mosby; 1995:177-215.

17. AOAC/FAO/IAEA/IUPAC Expert Consultation. Guidelines for single-laboratory validation of analytical methods for trace-level concentrations of organic chemicals. In: Fajgelj A, Ambrus A, eds. Principles of Method Validation. Cambridge U.K.: Royal Society of Chemistry; 2000:179-252. 